\title{
Atypical Posterior Reversible Encephalopathy Syndrome due to Oral Tyrosine Kinase Inhibitor Cabozantinib: First Case Report
}

\author{
Anannya Patwari $^{a}$ Vineel Bhatlapenumarthi ${ }^{a}$ Sheila K. Pascual ${ }^{b}$ \\ aNorthern Light Eastern Maine Medical Center, Bangor, ME, USA; \\ ${ }^{b}$ Northern Light Cancer Center, Bangor, ME, USA
}

\section{Keywords}

Atypical posterior reversible encephalopathy syndrome $\cdot$ Tyrosine kinase inhibitors .

Cabozantinib $\cdot$ Hypertension

\section{Abstract}

We report here a rare case of atypical posterior reversible encephalopathy syndrome (PRES) due to oral tyrosine kinase inhibitor cabozantinib. No case reports of such have been found in our literature search. The patient, a 70-year-old female with metastatic renal cell cancer on oral tyrosine kinase inhibitor cabozantinib, was brought into the emergency room because of confusion and seizures, found to have elevated blood pressure and atypical MRI findings consistent with PRES due to cabozantinib.

(C) 2020 The Author(s)

Published by S. Karger AG, Basel

\section{Introduction}

Posterior reversible encephalopathy syndrome (PRES) is a combination of clinical and radiological findings. It was first described by Hinchey et al. in 1996 in 15 patients who presented with neurological symptoms such as headache, altered mental status, visual disturbances, and seizures [1]. Imaging findings typically include vasogenic edema with involvement of the parietooccipital, posterior frontal cortical, and subcortical white matter best seen on MRI brain [2]. Atypical findings on MRI are not uncommon. A variety of medical conditions can cause PRES; they include uncontrolled hypertension, eclampsia, immunosuppressive/ 
Fig. 1. T2 flair sagittal section of MRI showing hyperintense foci involving frontal lobe (arrow).

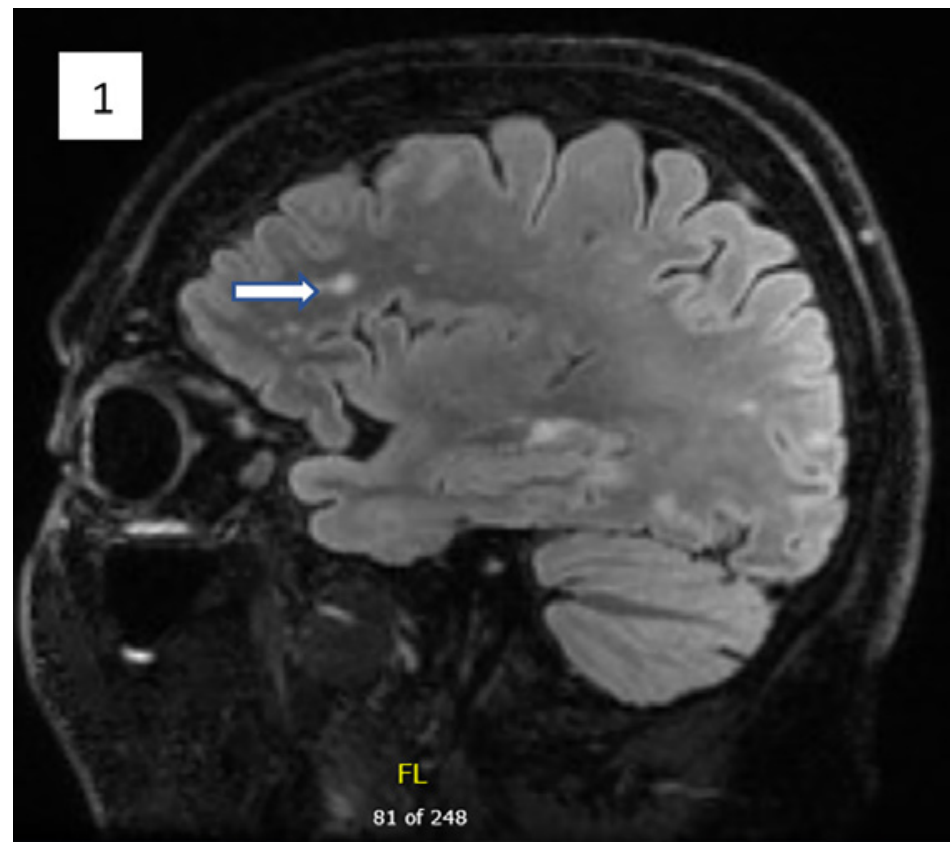

chemotherapy medications, anti-angiogenesis inhibitors, sepsis, and autoimmune disorders [3]. The exact incidence of PRES is not known. The exact pathogenesis is not clear, but the possible mechanisms include breakdown of the cerebral auto-regulation due to hypertension, endothelial dysfunction, vasospasm, and subsequent ischemia [3]. Here we described a case of PRES with atypical MRI findings due to oral tyrosine kinase inhibitor cabozantinib.

\section{Case Report}

A 70-year-old female with past medical history of metastatic renal cell carcinoma on palliative cabozantinib, chronic kidney disease, and essential hypertension well controlled at baseline was brought into the emergency room by family due to confusion and seizures preceded by nausea and vomiting. Patient has no prior history of seizures. Her oncological history was significant for diagnosis of metastatic right-sided renal cell carcinoma with metastasis to thoracic spine resulting in compression fracture requiring laminectomy and radiation therapy. She underwent right-sided nephrectomy as she developed spontaneous subscapular perinephric hematoma. Initially, she was treated with combination of ipilimumab and nivolumab and then was on nivolumab for 7 months and following which she was started on palliative cabozantinib 3 weeks prior to hospital admission in view of disease progression.

En route to the hospital she had an episode of seizure in the ambulance and was given intravenous lorazepam. When she initially presented to the hospital, her vitals were: heart rate 107 , afebrile, blood pressure $185 / 96 \mathrm{~mm} \mathrm{Hg}$, and respiratory rate of $28 / \mathrm{min}$. She was quite somnolent on initial exam, pupils were $4 \mathrm{~mm}$ and sluggishly reactive, remainder of the neurological exam was benign and non-focal. Patient required intubation to protect her airway. Blood work was unremarkable except for elevated creatinine at 1.59, which was at her baseline. CT scan of the brain did not show any bleed or acute intracranial process.

Levetiracetam was started on admission for seizures and nicardipine drip, given uncontrolled blood pressures. An EEG was done, which showed symmetric, nonspecifically slow,

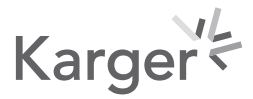




\section{Case Reports in Oncology}

Fig. 2. T2 flair sagittal section of MRI showing hyperintense foci involving parietal lobe (arrow).

\begin{tabular}{l|l}
\hline Case Rep Oncol 2020;13:1013-1019 \\
\hline DOI: 10.1159/000509640 & $\begin{array}{l}\text { @ 2020 The Author(s). Published by S. Karger AG, Basel } \\
\text { www.karger.com/cro }\end{array}$ \\
\hline
\end{tabular}

Patwari et al.: Atypical PRES due to Cabozantinib

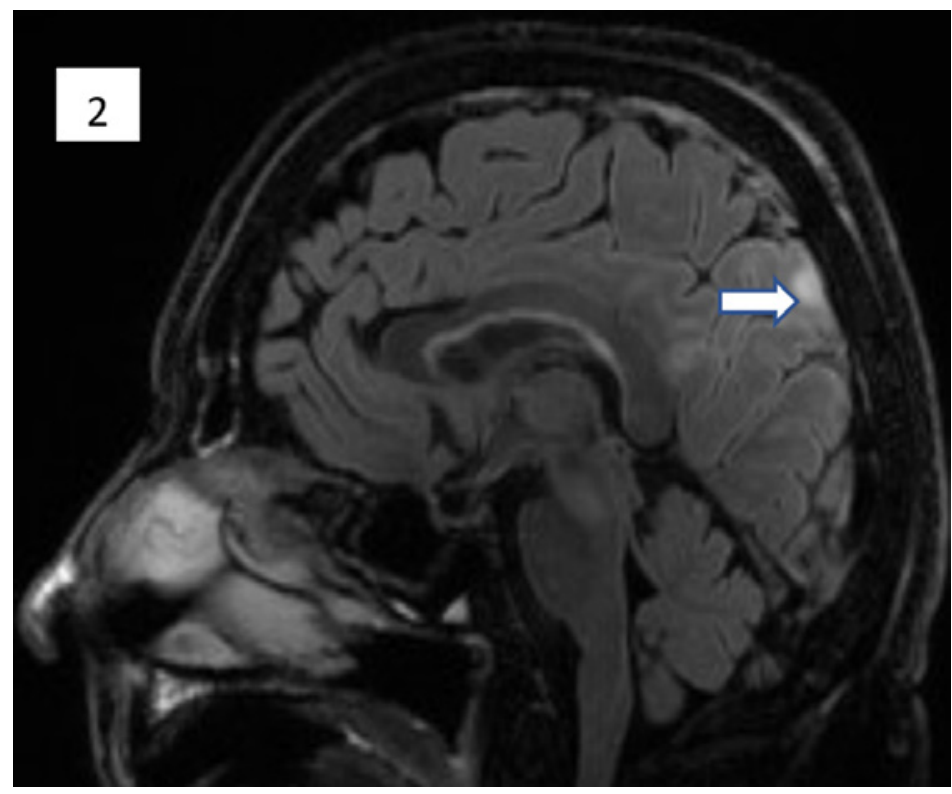

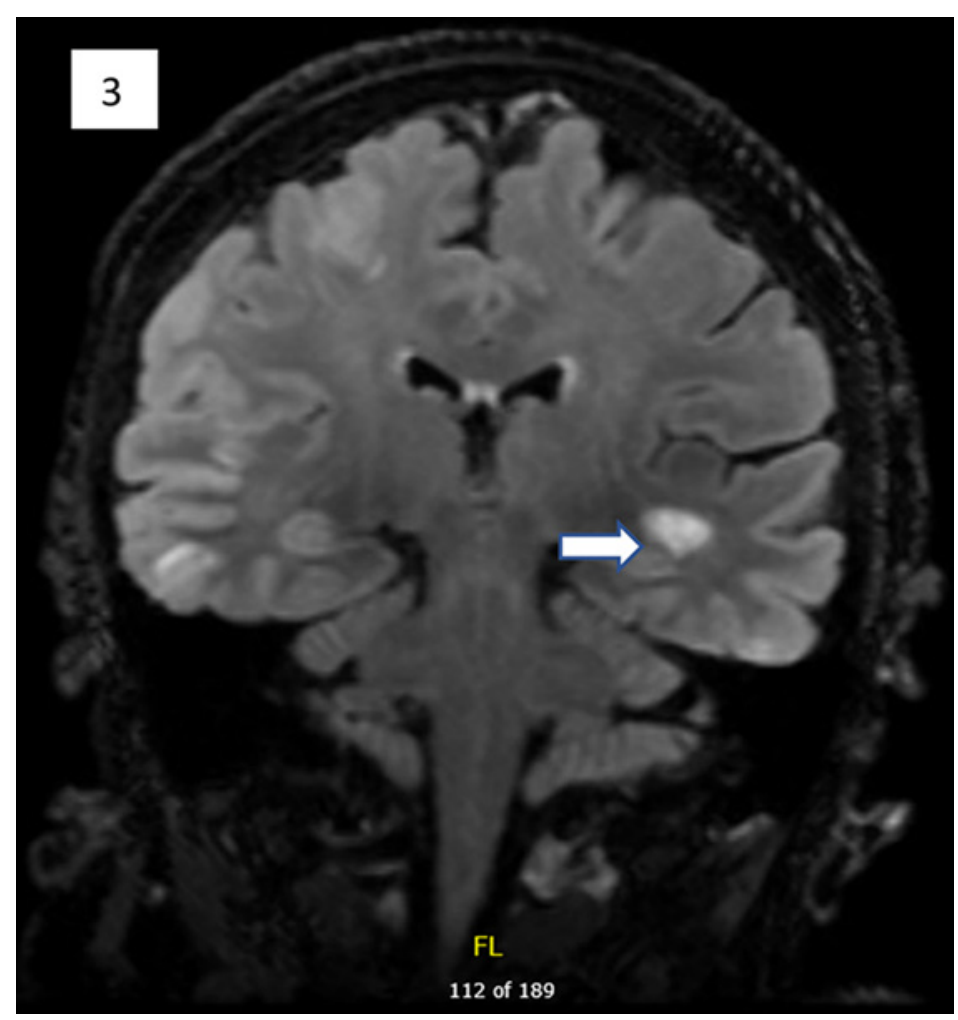

Fig. 3. T2 flair coronal section of MRI showing hyperintense foci involving temporal lobe (arrow).

mixed-frequency activities partly reflecting effects of pharmacologic sedation; there was no definite epileptiform activity. MRI of the brain with and without contrast was done, which showed multiple patchy subcortical T2/FLAIR hyperintense foci involving the frontal lobe (Fig. 1), parietal lobe (Fig. 2), temporal lobe (Fig. 3), and occipital lobe (Fig. 4). The T2 hypertense focus in the left temporal lobe has diffusion restriction (Fig. 5). There was diffuse mild leptomeningeal enhancement in the right frontal lobe, right parietal lobe, right temporal lobe, 


\section{Case Reports in Oncology}

Fig. 4. T2 flair sagittal section of MRI showing hyperintense foci involving occipital lobe (arrow).

\begin{tabular}{l|l}
\hline Case Rep Oncol 2020;13:1013-1019 \\
\hline DOI: 10.1159/000509640 & $\begin{array}{l}\text { @ 2 2020 The Author(s). Published by S. Karger AG, Basel } \\
\text { www.karger.com/cro }\end{array}$ \\
\hline
\end{tabular}

Patwari et al.: Atypical PRES due to Cabozantinib

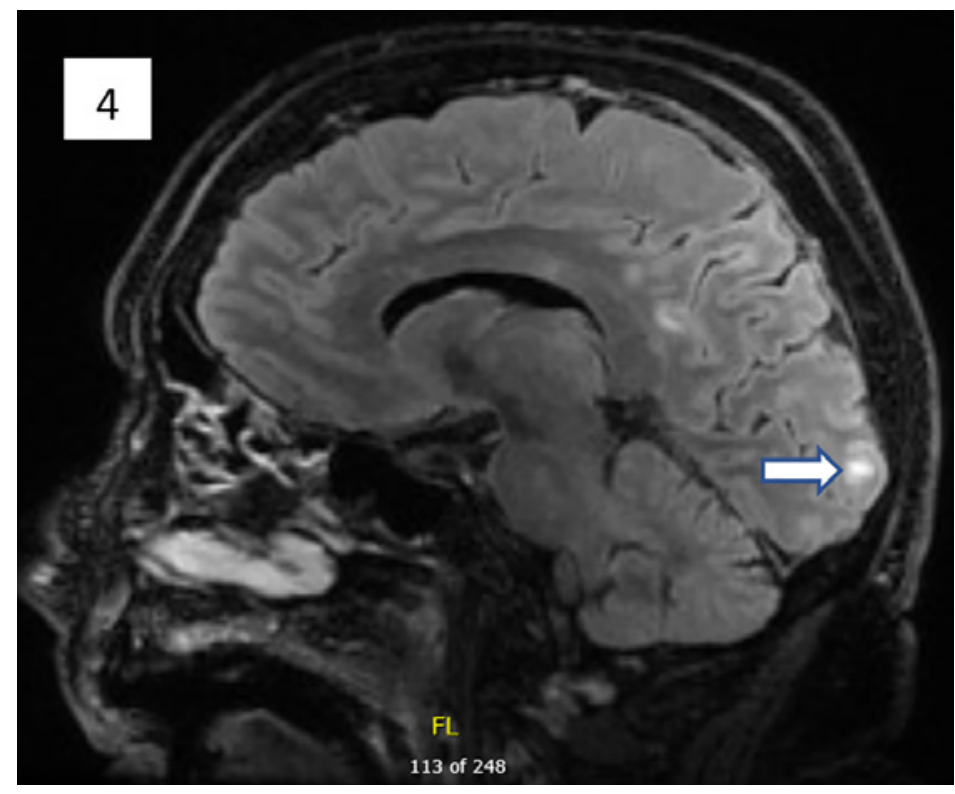

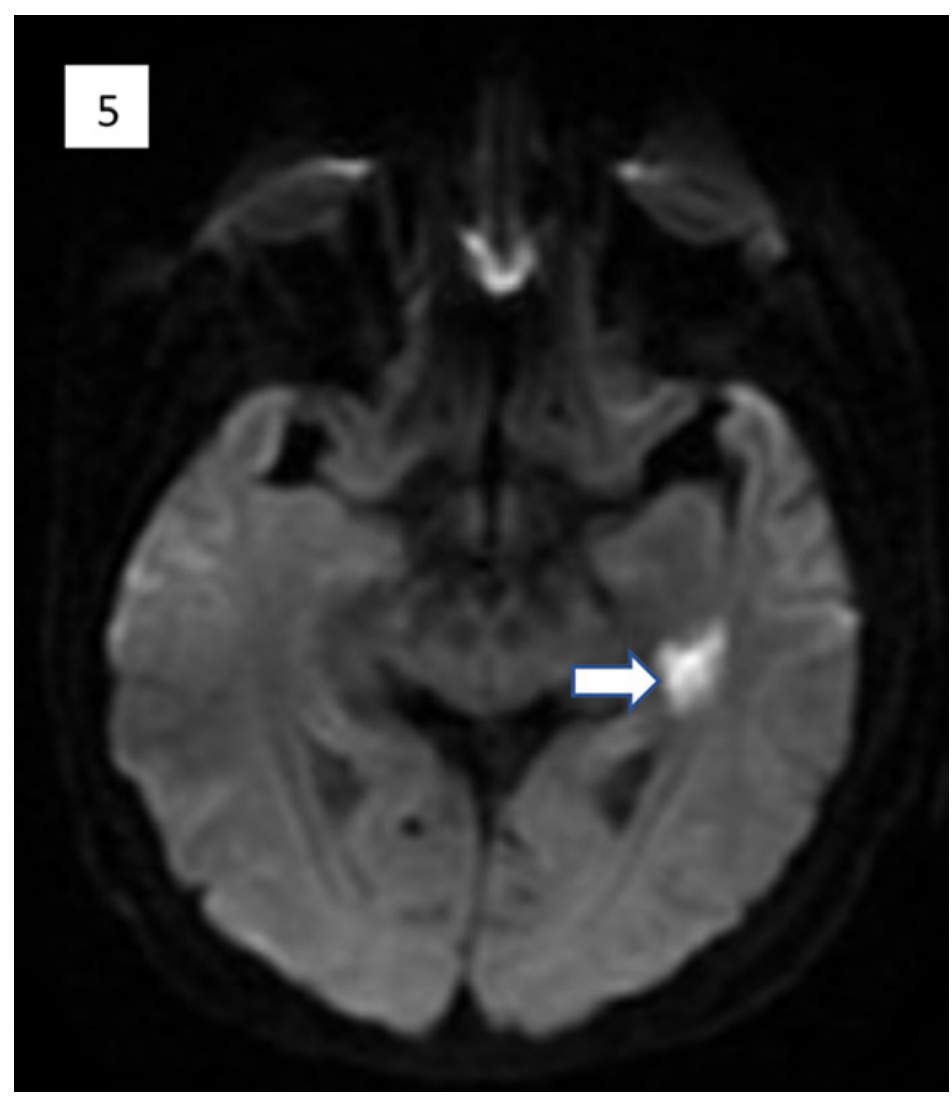

Fig. 5. Diffusion restriction of MRI showing hyperintense foci in temporal lobe (arrow).

and bilateral occipital lobes (Fig. 6). She was diagnosed with atypical PRES by Neurology given her clinical presentation and MRI findings.

Her presentation was felt to be secondary to uncontrolled hypertension from cabozantinib, an oral tyrosine kinase inhibitor leading to PRES syndrome. Given her high blood 


\section{Case Reports in Oncology}

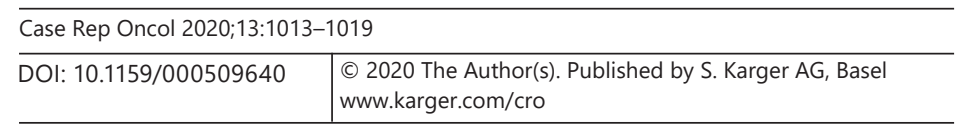

Patwari et al.: Atypical PRES due to Cabozantinib

Fig. 6. MRI showing meningeal enhancement (arrows).

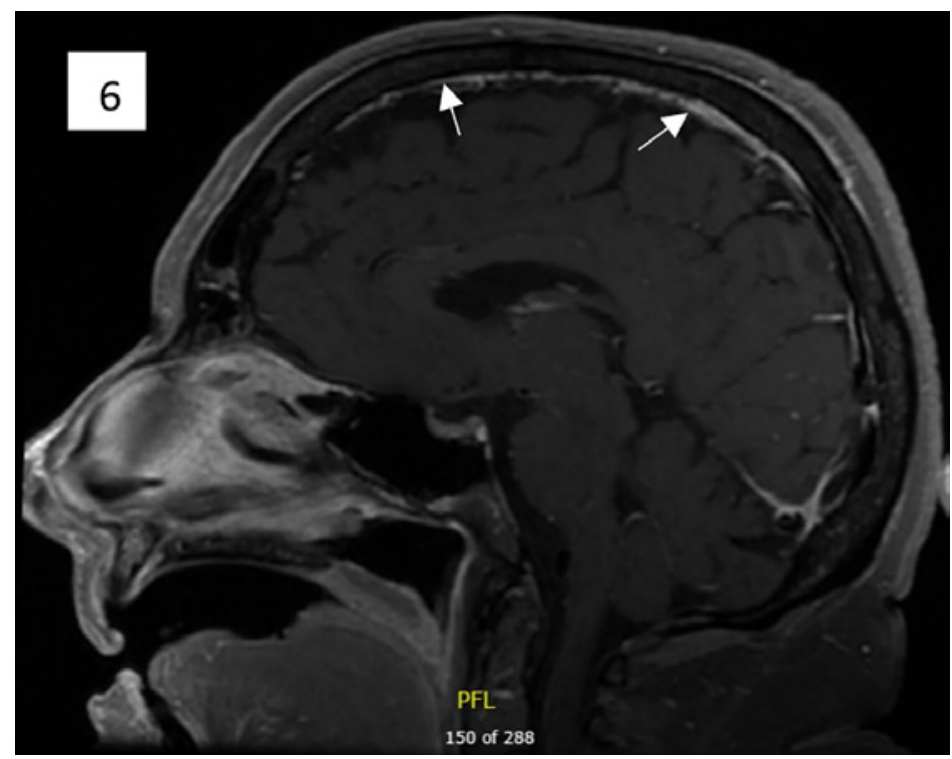

pressure she required aggressive control initially with IV nicardipine drip and was subsequently switched to oral anti-hypertension medications metoprolol and amlodipine. She did not have further recurrence of seizures while in the hospital and was extubated within $24 \mathrm{~h}$ of hospital admission, her mental status gradually improved to baseline within $48 \mathrm{~h}$ of hospital admission. Cabozantinib was discontinued on discharge. Levetiracetam was continued on discharge and plan was to have a follow-up MRI of the brain in 3 months to look for resolution of MRI findings. Unfortunately, she had disease progression and patient elected to transition to hospice.

\section{Discussion}

Chemotherapeutic agents are one of the causes of PRES. There are multiple chemotherapeutic agents that are associated with PRES including taxanes, platinum derivatives, vinca alkaloids, antimetabolites, anthracyclines, angiogenesis inhibitors, folate antagonists, and immunosuppressants [4]. Angiogenesis inhibitors include group of chemotherapeutic agents that block vascular endothelial growth factor (VEGF) function in different ways. These include anti-VEGF antibodies (bevacizumab), soluble VEGF decoy receptors (aflibercept), anti-VEGF receptor antibodies (ramucirumab), and tyrosine inhibitors like sorafenib, sunitinib, pazopanib, and cabozantinib. Angiogenesis inhibitors can cause hypertension as VEGF plays a key role in the maintenance of vascular homeostasis via mediation of the production of the vasodilator nitric oxide and decreased vascular resistance through the generation of new blood vessels [5]. Anti-angiogenic therapy-induced PRES is most likely a consequence of systemic arterial hypertension and endothelial dysfunction from direct injury leading to dysfunction at the level of the blood-brain barrier with resultant vasogenic edema [6].

Cabozantinib is a multi-kinase inhibitor targeting VEGF receptor (VEGFR) 2, mesenchymal-epithelial transition receptor, and anexelekto receptor tyrosine kinase. Hypertension has been reported in 37\% of patients on cabozantinib in the METEOR trial and 15\% had grade 3 or higher [7]. In the CABOSUN trial, $81 \%$ of patients on cabozantinib reported hypertension and $28 \%$ had grade 3 or higher [8]. Studies showed multiple VEGF inhibitors are associated

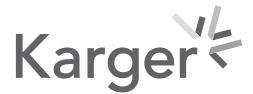


with PRES [9-13]. There have been no studies found in our literature search with cabozantinib causing PRES.

Typically, PRES leads to symmetric hemispheric vasogenic edema in the subcortical white matter best seen on T2/FLAIR sections on MRI with absence of restricted diffusion predominantly involving parietal and occipital lobes. There can be also atypical presentation of PRES where there can be involvement of deep gray nuclei, brainstem/cerebellar hemispheres. Diffusion restriction, leptomeningeal contrast enhancement, and hemorrhage are not uncommon [14-16]. Our patient had atypical features of PRES including restricted diffusion on DWI and leptomeningeal contrast enhancement.

A study on PRES due to VEGF inhibitors has shown that PRES induced by anti-VEGF agents is more common in females and median duration for onset of PRES following anti-VEGF therapy was 9.5 weeks. The risk of PRES is increased when blood pressure is poorly controlled and neurological outcome was favorable in all cases with symptomatic treatment [17]. Management involves supportive care with aggressive control of blood pressure with intravenous agents, seizure control, and some patients may require protection of airway with intubation as in our case. Seizures can be controlled using benzodiazepines and antiepileptic agents for the acute management. However, they can be tapered in patients without seizure recurrence and after resolution of MRI abnormalities [17]. Anti-VEGF therapy should be suspended at least for short term and may have to be resumed in patients who have limited therapeutic options especially in metastatic setting with aggressive control of blood pressure [18].

When patients are started on cabozantinib, it is vital to emphasize the importance of regular monitoring and aggressive control of blood pressure. Thresholds for initiating and the choice of antihypertensive agents should be based on the patient's cardiovascular comorbidities and guidelines on the management of hypertension. If patients do not have cardiovascular comorbidity, angiotensin receptor blockers may be the agent of choice as they have been shown to inhibit angiotensin II-mediated growth and migration of cancer cells and angiogenesis. $\beta$-Blockers may also have some role in reducing hypertension induced by VEGF pathway inhibitors as they have shown to induce apoptosis in endothelial cells [19]. Our patient was started on amlodipine and metoprolol, which controlled her blood pressure well; ACE inhibitors were not used due to her underlying kidney disease. Patient, followed with oncology closely as outpatient, unfortunately had progression of the underlying renal cell cancer and she chose hospice.

\section{Conclusion}

PRES due to chemotherapeutic agents is not uncommon. Diagnosis is with appropriate clinical and radiological findings. VEGF inhibitors are notorious to cause hypertension and PRES is a severe manifestation of uncontrolled hypertension. Cabozantinib is an oral tyrosine kinase inhibitor that blocks the VEGF pathway and is used in the treatment of renal cell cancer that can cause hypertension. We have here reported the first case of PRES due to cabozantinib. Clinicians should have a high suspicion of PRES in the right clinical setting especially when on VEGF inhibitors. It is very critical to have close monitoring and austere blood pressure control.

\section{Statement of Ethics}

The patient has given written informed consent to publish the case (including publication of images). The manuscript has been sufficiently de-identified to protect the patient identity. 


\section{Conflict of Interest Statement}

The authors have no conflicts of interest to declare.

\section{Funding Sources}

None.

\section{Author Contributions}

Vineel Bhatlapenumarthi has contributed to the drafting and editing of the manuscript. Sheila K. Pascual has contributed to the editing of the manuscript.

\section{References}

1 Hinchey J, Chaves C, Appignani B, Breen J, Pao L, Wang A, et al. A reversible posterior leukoencephalopathy syndrome. N Engl J Med. 1996;334(8):494-500.

2 McKinney AM, Short J, Truwit CL, McKinney ZJ, Kozak OS, SantaCruz KS, et al. Posterior reversible encephalopathy syndrome: incidence of atypical regions of involvement and imaging findings. AJR Am J Roentgenol. 2007;189(4):904-12.

3 Fugate JE, Claassen DO, Cloft HJ, Kallmes DF, Kozak OS, Rabinstein AA. Posterior reversible encephalopathy syndrome: associated clinical and radiologic findings. Mayo Clin Proc. 2010;85(5):427-32.

4 Cacho-Díaz B, Lorenzana-Mendoza NA, Salmerón-Moreno K, Castillo-Rangel C, Corona-Cedillo R, et al. Chemotherapy-induced posterior reversible encephalopathy syndrome. Medicine. 2019;98(19):e15691.

5 Reyes-Soto DA. Angiogenesis inhibitors and hypertension: an emerging issue. J Clin Oncol. 2006;24(9):1329-31.

6 Lam JYC, Ng MCH. Posterior reversible encephalopathy syndrome and anti-angiogenic therapy. Proc Singapore Healthc. 2014;23(3):241-5.

7 Choueiri TK, Escudier B, Powles T, Mainwaring PN, Rini BI, Donskov F, et al. Cabozantinib versus Everolimus in Advanced Renal-Cell Carcinoma. N Engl J Med. 2015;373(19):1814-23.

8 Choueiri TK, Hessel C, Halabi S, Sanford B, Michaelson MD, Hahn O, et al. Cabozantinib versus sunitinib as initial therapy for metastatic renal cell carcinoma of intermediate or poor risk (Alliance A031203 CABOSUN randomised trial): progression-free survival by independent review and overall survival update. Eur J Cancer. 2018;94:115-25.

9 Hamid M, Ghani A, Micaily I, Sarwar U, Lashari B, Malik F. Posterior reversible encephalopathy syndrome (PRES) after bevacizumab therapy for metastatic colorectal cancer. J Community Hosp Intern Med Perspect. 2018;8(3):130-3.

10 Chen H, Modiano MR, Neal JW, Brahmer JR, Rigas JR, Jotte RM, et al. A phase II multicentre study of zivaflibercept in combination with cisplatin and pemetrexed in patients with previously untreated advanced/ metastatic non-squamous non-small cell lung cancer. Br J Cancer. 2014;110(3):602-8.

11 Deguchi S, Mitsuya K, Nakasu Y, Hayashi N, Katagiri H, Murata H, et al. Posterior reversible encephalopathy syndrome (PRES) induced by pazopanib, a multi-targeting tyrosine kinase inhibitor, in a patient with softtissue sarcoma: case report and review of the literature. Invest New Drugs. 2018;36(2):346-9.

12 Kapiteijn E, Brand A, Kroep J, Gelderblom H. Sunitinib induced hypertension, thrombotic microangiopathy and reversible posterior leukencephalopathy syndrome. Ann Oncol. 2007;18(10):1745-7.

13 Ozcan C, Wong SJ, Hari P. Reversible posterior leukoencephalopathy syndrome and bevacizumab. N Engl J Med. 2006;354(9):980-2.

14 Saad AF, Chaudhari R, Wintermark M. Imaging of Atypical and Complicated Posterior Reversible Encephalopathy Syndrome. Front Neurol. 2019;10:964.

15 Karia SJ, Rykken JB, McKinney ZJ, Zhang L, McKinney AM. Utility and Significance of Gadolinium-Based Contrast Enhancement in Posterior Reversible Encephalopathy Syndrome. AJNR Am J Neuroradiol. 2016;37(3):415-22.

16 Covarrubias DJ, Luetmer PH, Campeau NG. Posterior reversible encephalopathy syndrome: prognostic utility of quantitative diffusion-weighted MR images. AJNR Am J Neuroradiol. 2002;23(6):1038-48.

17 Kastrup 0, Gerwig M, Frings M, Diener HC. Posterior reversible encephalopathy syndrome (PRES): electroencephalographic findings and seizure patterns. J Neurol. 2012;259(7):1383-9.

18 Tlemsani C, Mir O, Boudou-Rouquette P, Huillard O, Maley K, Ropert S, et al. Posterior reversible encephalopathy syndrome induced by anti-VEGF agents. Target Oncol. 2011;6(4):253-8.

19 Schmidinger M, Danesi R. Management of Adverse Events Associated with Cabozantinib Therapy in Renal Cell Carcinoma. Oncologist. 2018;23(3):306-15. 